\title{
RISK AND BENEFITS ASSOCIATED WITH INTERNATIONAL CONSTRUCTION/ CONSULTING JOINT VENTURES IN THE ENGLISH-SPEAKING CARIBBEAN
}

\author{
Karl Mclntosh - Graduate Student, Dept of Civil Engineering, University of Toronto, Canada \\ Brenda McCabe - Associate Professor, Dept. of Civil Engineering, University of Toronto, \\ Canada
}

\begin{abstract}
Research was undertaken to determine the major risk factors associated with international construction joint ventures (ICJV) formed in the English-speaking Caribbean (ESC) with construction and consulting firms from Canada and the United States of America. The top three reasons for forming ICJV are to improve competitive positions, enter new markets, and share risks and/or profits. The top three benefits of the ICJV are enhancement of competitive position, obtain new work, and to increase market share. There was some correlation between reasons for entering into these relationships and their perceived benefits. The top three risks were loss due to bureaucracy for late approvals, project delay, and client's cash flow problems. The top ten risks for both English speaking Caribbean and North American firms were identical although the ranks changed slightly.
\end{abstract}

KEYWORDS: Construction management, international, risk factors, joint ventures, success factors

\section{BACKGROUND}

With the increase in competition for business brought on by globalization and the opening of national borders, companies continue to look for ways to remain competitive. This challenge extends to the construction industry, resulting in several firms looking outside of their countries for opportunities. Many of these companies do not plan to set up new offices overseas as that brings high overhead expenses. It is apparent, however, that as investments are injected into developing countries and several new projects are considered, technical expertise is needed. Engineering and construction companies in many of these developing countries are unable to carry out larger projects on their own and therefore look toward firms in the developed nations for assistance (Tulacz 2000a).

There has been a great increase in the number of foreign construction and consulting companies entering the English-speaking Caribbean (ESC) local market to conduct business. The most common strategy used by several firms originating in the United States or Canada is the formation of joint ventures with ESC firms on a project-by-project basis. There are several risks associated with these international construction/consulting joint ventures (ICJV), therefore proper assessment and management of the risk should be performed before agreements are signed (Shen et al. 2001; Bing et al. 1999).

The ESC is a close neighbour to North America and over the past few years it has seen a great influx of North American (NA) firms competing for construction projects. Due to the differences in management systems, technological practice, and cultural background, the construction operations and practices will differ for these regions. The firms entering the market in the ESC, especially for the first time, should be aware of the risks associated with these differences to ensure that proper management tools are in placed to evaluate, assess and mitigate the risks.

\section{Research Objectives}

The objectives of this research were to: 
1. Identify the primary motivations for both the international (NA) and the local (ESC) companies to enter into an ICJV,

2. Determine the benefits gained by both partners in an ICJV,

3. Identify and rank the major risk factors that influence the success of the ICJV, and,

4. Compile strategies for mitigating risk factors in ICJVs.

\section{Research Scope and Methodology}

A literature review helped to identify the main risk factors involved in international construction. Next, a questionnaire was developed to identify which of those ICJV risks are associated with the ESC. For risk factor, the participants were asked to identify according to their experience:

- The likelihood of occurrence of each risk as low, moderate or high, and,

- The degree of impact, small, moderate or high, that would result on the joint venture and on the project should the risk materialize.

Interviews were conducted with industry personnel from both partners of the ICJV. Finally, the survey results were analyzed and the risk factors ranked in order of their importance.

\section{CONSTRUCTION IN THE ENGLISH-SPEAKING CARIBBEAN}

Some of the major concerns that must be addressed before the decision is made to enter a new country and new market include the socio-cultural factors, economic factors and technological considerations. The risks should be assessed and a process for managing them implemented.

Before the ESC is considered a viable area in which international construction / consulting firms may invest, a closer look must be taken at the amount spent on construction in some of the major islands. Tulacz (2000b) presented the amount spent both as a dollar figure and as the percentage of the country's gross domestic product (\%GDP) over a three-year period 1998-2000. The rank is based on the spending of the 150 countries surveyed. The figures, shown in Table 1, were compared to Canada and the United States over the same time period. All values are in US dollars.

Table 1: Construction spending (Tulacz 2000b)

\begin{tabular}{rrrrrrrr}
\hline & \multicolumn{2}{c}{1998} & \multicolumn{2}{c}{1999} & \multicolumn{2}{c}{2000} \\
\multicolumn{1}{c}{ Country } & \%GDP & \$ Mil & \%GDP & \$ Mil & \%GDP & \$ Mil & Rank \\
\hline Bahamas & 5.8 & 243.0 & 6.0 & 273.6 & 6.0 & 287.4 & 123 \\
Barbados & 12.9 & 291.7 & 12.9 & 301.8 & 13.0 & 314.6 & 119 \\
Grenada & 8.3 & 28.5 & 8.3 & 29.8 & 8.21 & 30.8 & 150 \\
Jamaica & 11.4 & 734.2 & 11.0 & 677.1 & 11.9 & 740.8 & 97 \\
Trinidad \& Tobago & 8.9 & 565.4 & 9.1 & 638.2 & 8.9 & 666.4 & 102 \\
\hline Caribbean Total & & 1862.9 & & 1920.6 & & 2040.0 & \\
Canada & 10.3 & 59,758 & 10.1 & 62,062 & 10.2 & 65,235 & 11 \\
USA & 8.1 & 711,127 & 8.2 & 764,233 & 8.2 & 819,300 & 1 \\
\hline
\end{tabular}

The construction market of the ESC has increased steadily from $\$ 1.863$ billion in 1998 to $\$ 2.040$ billion in 2000 , a $9.5 \%$ increase. The spending in each island has also grown over the three-year period with the exception of Jamaica, which had a reduction in 1999 relative to 1998. These values may appear insignificant when compared to those of Canada and the U.S., but 
are resonable when compared on a GDP basis. The Bahamas spending in construction ranges from $5.8 \%$ to $6.0 \%$ of GDP, and is the smallest of the Caribbean islands. The other Islands are all comparable to the USA, which has spend on average $8.2 \%$ of GDP over the three year period on construction; Canada has an average of $10.2 \%$ of GDP over the same period.

\section{THE QUESTIONNAIRE}

Data collection was conducted between November 2001 and April 2002 via a detailed questionnaire and interviews. The companies were selected from:

- Engineering News Record (ENR) "The top 400 contractors", May 22, 2000: USA contractors that have conducted business in the Caribbean region.

- Engineering News Record (ENR) "The top 500 design firms", April 16, 2001: USA consultants that have conducted business in the Caribbean region.

- The assistance of the Consulting Engineers of Ontario to identify Canadian firms that have conducted work in the Caribbean.

- The various local professional boards and governmental organization in each region, as well as those firms and organizations with which the authors are acquainted.

Notification letters were mailed out to the managing directors or presidents of the companies introducing the research and requesting their input. After receiving a response stating their interest to participate in the research, the questionnaire was mailed.

Risks associated with forming an ICJV in China (Shen et al. 2001) and in East Asia (Bing et al. 1999) were adopted and classified into six groups namely, financial risks, legal risks, management risks, market risks, policy and political risks, and technical risks.

The questionnaire was divided into six sections. Section one was to obtain the organization's background information and its experience in ICJV primarily within the ESC. Section two was aimed at identifying the primary drivers for forming joint ventures. Section three identified the main success considerations that go into the establishment of these joint ventures. In Section four, a ranking of the benefits gained from the formation of joint ventures was sought. Identification of the factors that were considered to be the main ingredients that may lead to the joint venture being successful or unsuccessful was gained in Section five. Finally, Section six contained sixtyfour risk factors classified into the six categories. The respondents were asked to review and indicate the likelihood of occurrence of these risks as low, moderate or high and the degree of impact that would result as small, moderate or high. The option was also given to identify and list any additional risk factors that may have been overlooked. Four in-depth interviews were conducted to obtain additional information from respondents.

\section{Organization Background Information}

A total of 182 notification letters were mailed out to companies operating in the USA, Canada and the Caribbean requesting their participation in the research. Based on the responses, 147 questionnaires were mailed; from that number, 48 were returned, resulting in a response rate of $33 \%$. Several of the companies that had earlier noted their interest in completing the survey failed to do so noting that the questionnaire was too lengthy or that they were too busy. The distribution of respondents according to nationality is shown in Table 3 and according to their field of construction in Table 2.

Respondents were asked to indicate the length of time that their company has been in operation

and how much of this time they have been involved in ICJV. 
Figure 1 shows a comparison of the company's years in international construction compared with their time in operation. It is noted that the majority of the respondents have been in operation for more than twenty years and possess international construction experience in excess of fifteen years. All respondents have been involved in one or more ICJV in the English-speaking Caribbean.

Table 2: Field of Construction

\begin{tabular}{lc}
\hline Field & Number of respondents \\
\hline Engineering design & 29 \\
Design/Build & 17 \\
Architectural design & 1 \\
Engineering/Architectural & 1 \\
Construction only & 0 \\
Total & 48 \\
\hline
\end{tabular}

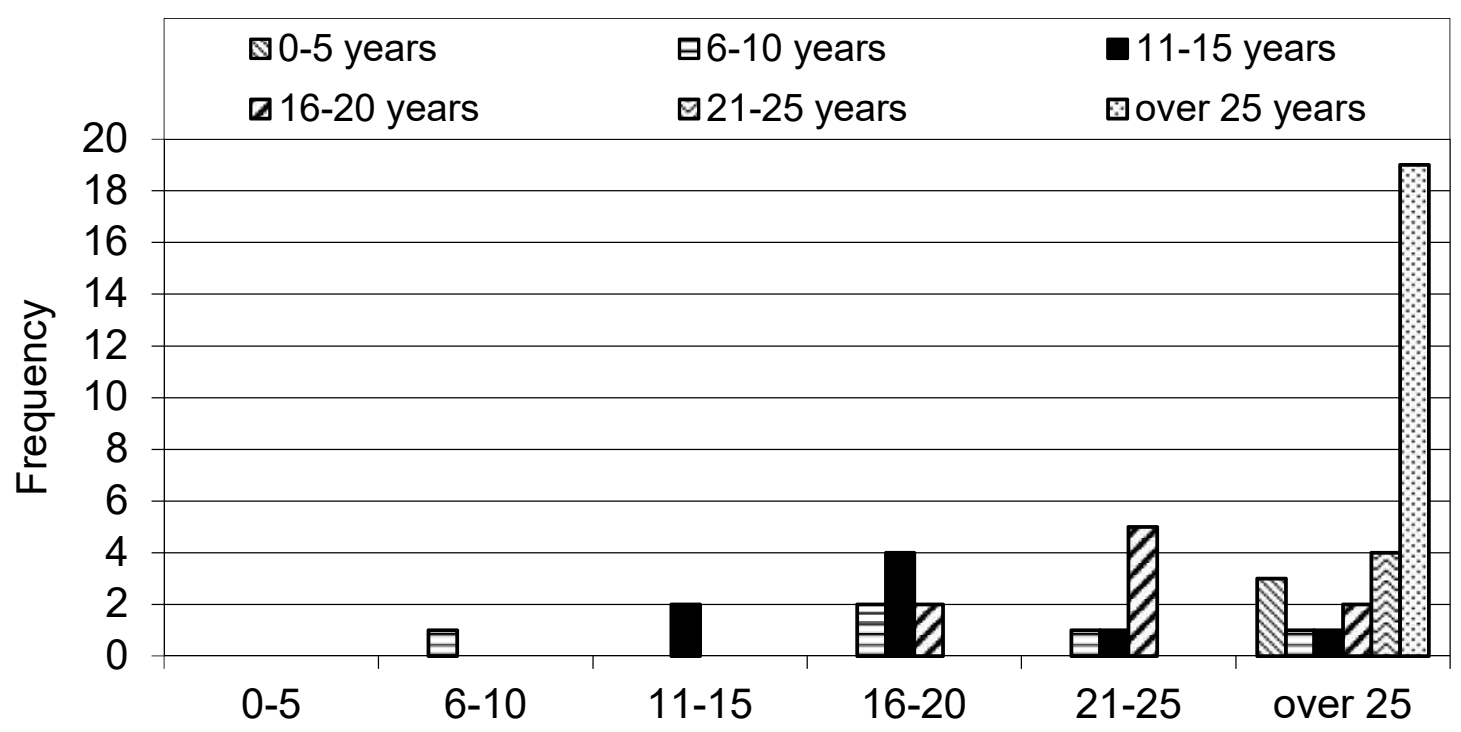

Years in Operation

Figure 1: Years in international construction compared with years in operation

Table 3: Profiles of Respondent by Nationality

\begin{tabular}{lcccc}
\hline Country & $\begin{array}{c}\text { Number of } \\
\text { notification letters }\end{array}$ & $\begin{array}{c}\text { Number of } \\
\text { surveys }\end{array}$ & $\begin{array}{c}\text { Number of } \\
\text { respondents }\end{array}$ & $\begin{array}{c}\% \\
\text { Responses }\end{array}$ \\
\hline USA & 99 & 75 & 15 & 20 \\
Canada & 31 & 20 & 7 & 35 \\
Jamaica & 25 & 25 & 14 & 56 \\
Trinidad \& Tobago & 17 & 17 & 9 & 53 \\
Barbados & 4 & 4 & 2 & 50 \\
Guyana & 1 & 1 & 1 & 100 \\
Antigua & 2 & 2 & 0 & 0 \\
St. Vincent \& the Grenadines & 3 & 3 & 0 & 0 \\
Total & 182 & 147 & 48 & 33 \\
\hline
\end{tabular}


The number of ESC-based international construction joint ventures in which these companies were involved, shown in Figure 2, shows a definite trend in these activities. The total number of ICJV increased steadily over the last 3 decades. Before 1970 the North American companies surveyed undertook only one ICJV, increasing to 51 in the 1990s. Between January 2000 and April 2002, 45 joint ventures were formed indicating that if these companies continue investing at the same rate through the decade, the previous total of 51 should be well exceeded. Similarly for the Caribbean respondents, no joint ventures were formed by this group before 1970, and exploded to 81 in the 1990s. From January 2000 to April 2002, 50 joint ventures had already been formed.

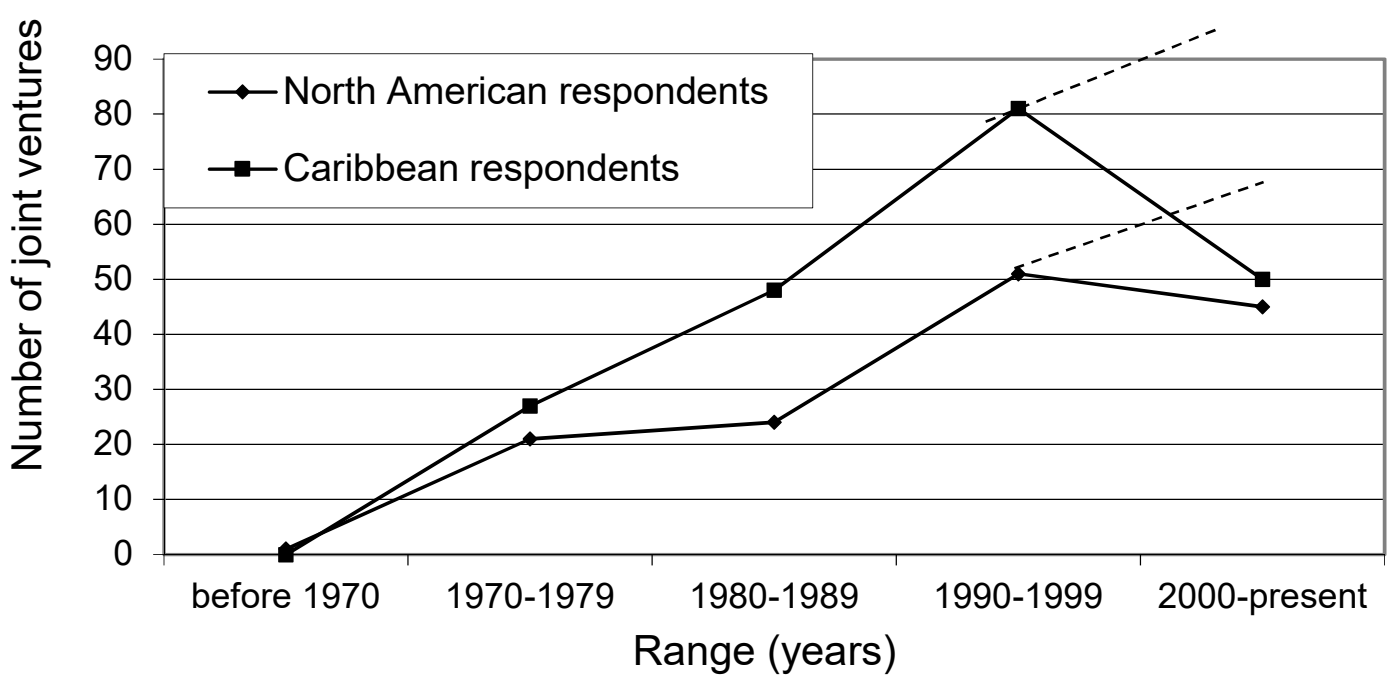

Figure 2: Total number of ICJV 1970-present

The importance of ICJV as a percentage of the companies' total work is shown in Table 4. Presently, international work accounts for less than $25 \%$ of most companies' total work. Interviews attributed this to the recent increase in the North American construction market, where international firms are able to find a lot more work at home. Investing in the international market is done not because of the need for new work but to gain experience in those markets for future benefits. Another reason noted was to maintain service to long-standing clients who were conducting construction projects in the region.

Government funded projects in the ESC Table 4: Percentage of work attributed to ICJV were shown to be most common, as shown in Table 5. Of the 48 respondents, 35 had the majority of their projects funded by the government; these projects were generally larger than privately funded projects and were sometimes more technologically demanding.

\begin{tabular}{cc}
\hline Range $(\%)$ & Number of respondents \\
\hline Less than $10 \%$ & 28 \\
$10-25 \%$ & 16 \\
$26-50 \%$ & 2 \\
$51-75 \%$ & 1 \\
$76-100 \%$ & 1 \\
Total & 48 \\
\hline
\end{tabular}

Firms form joint ventures with organizations from their own countries as well as with companies from other countries. Table 6 shows the main concerns that the NA firms used in forming a joint venture in the ESC. Most of the joint ventures with USA or Canadian firms are formed with well- 
known firms where their capabilities are not in doubt. Little is known about the firms operating in the ESC and therefore the NA companies entering these joint ventures are normally unsure about their technological capabilities. The other factors such as cultural differences, governmental requirements and financial requirements are not as critical.

Table 5: Method of Funding

\begin{tabular}{cc}
\hline Field & Number of respondents \\
\hline Government & 35 \\
Private & 12 \\
Other & 1 \\
Total & 48 \\
\hline
\end{tabular}

learn new markets, meet government requirements, and, secure financing. The arithmetic means of the individual ranking were calculated to determine the rank, as shown in

Table 7.

To improve competitive position was ranked number one by both the NA and the ESC firms. As shown in Figure 3, this criterion was ranked 1 by 15 of the 26 ESC respondents, but by only 6 of the 22 NA respondents. Many firms noted that forming joint ventures with the right firm in the right country could give them the advantage to improve their competitive position. In such a joint venture, the NA firm is sharing the ESC firm's knowledge of the local market. The ESC firms on the other hand, seek to gain the NA company's technological and management skills.

\section{Primary motivation for forming ICJV}

The respondents were asked to place in order of priority ( 1 being the most important) based on their corporate objectives, eight motivating factors (CII 1993) for forming ICJV, namely, improve competitive position, enter new markets, share risk and/or profits, access technology, serve core customers,

Table 6: NA companies' main concerns with ESC companies

\begin{tabular}{cc}
\hline Response & $\begin{array}{c}\text { Number of } \\
\text { respondents }\end{array}$ \\
\hline Technological capabilities & 15 \\
Governmental requirements & 5 \\
Cultural differences & 4 \\
Financial requirements & 1 \\
\hline
\end{tabular}

Table 7: Drivers for forming joint ventures

\begin{tabular}{ccccc}
\hline & \multicolumn{2}{c}{ Caribbean } & \multicolumn{2}{c}{ North American } \\
Factors & Rank & Mean & Rank & Mean \\
\hline $\begin{array}{c}\text { Improve competitive } \\
\text { position }\end{array}$ & 1 & 1.7 & 1 & 2.3 \\
$\begin{array}{c}\text { Enter new markets } \\
\text { To share risk and /or }\end{array}$ & 5 & 4.5 & 2 & 2.8 \\
$\quad$ profits & 3 & 3.5 & 4 & 3.8 \\
Access Technology & 2 & 2.5 & 8 & 7.2 \\
Serve core customers & 4 & 4.4 & 6 & 5.2 \\
Learn local markets & 8 & 7.4 & 3 & 3.4 \\
Meet gov't requirements & 7 & 6.4 & 5 & 4.5 \\
Secure financing & 6 & 5.6 & 7 & 6.9 \\
\hline
\end{tabular}

Firms may form an international construction joint venture for a single project as a first step in developing a long-term presence in a new market, allowing them to first get an understanding of the governmental polices and other important issues. Enter new markets was very important to the North American firms as shown in Figure 4. 


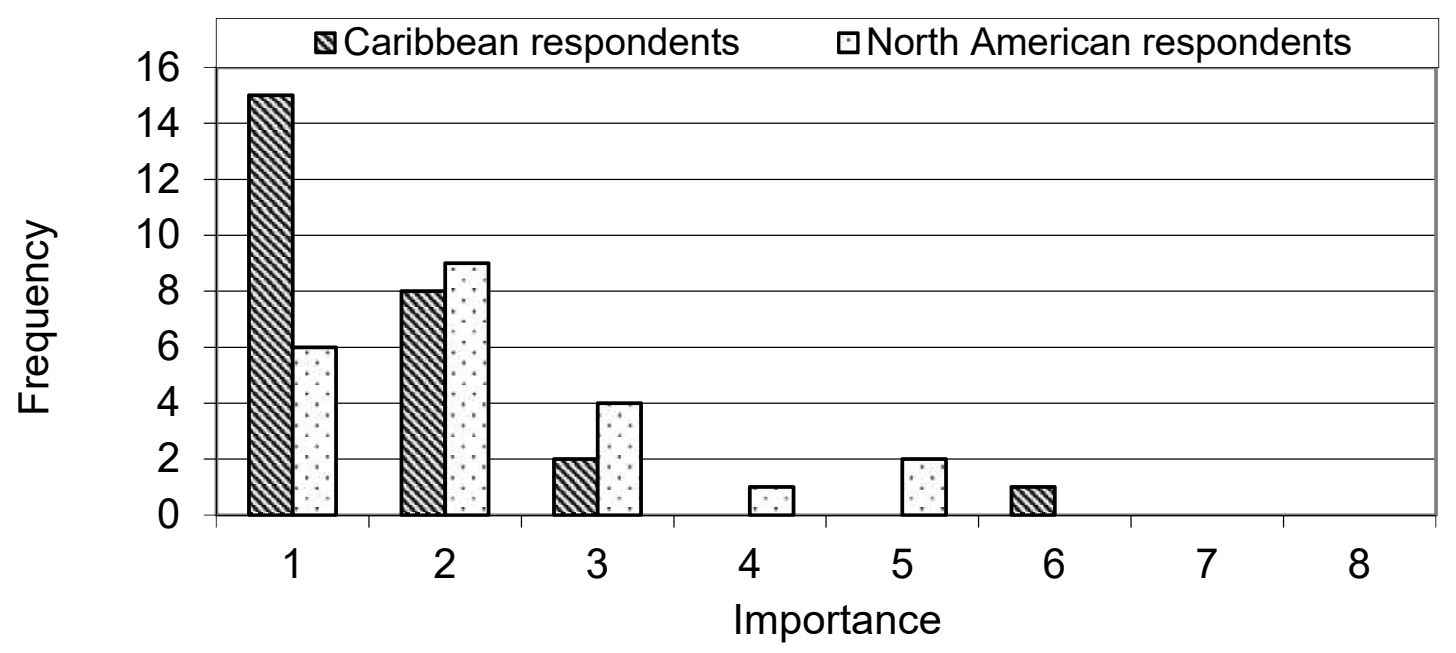

Figure 3: Improve competitive position

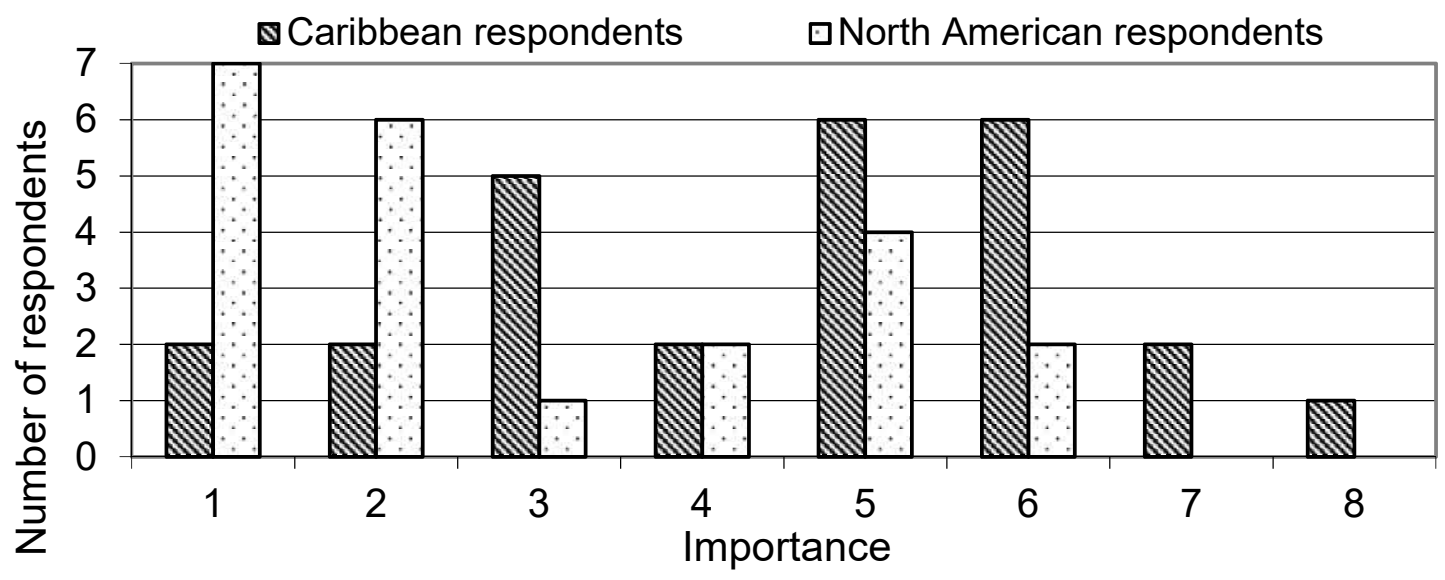

Figure 4: Enter new markets

Sharing risks and /or profits: Formation of a joint venture allows risks to be shared, as it helps to reduce the uncertainties of doing work in new geographic locations (CII 1993). Sharing risk was ranked number 3 by the ESC firms and number 4 by the NA companies. Only 2 of the 22 NA firms gave this criterion a ranking of 1 , as shown in Figure 5.

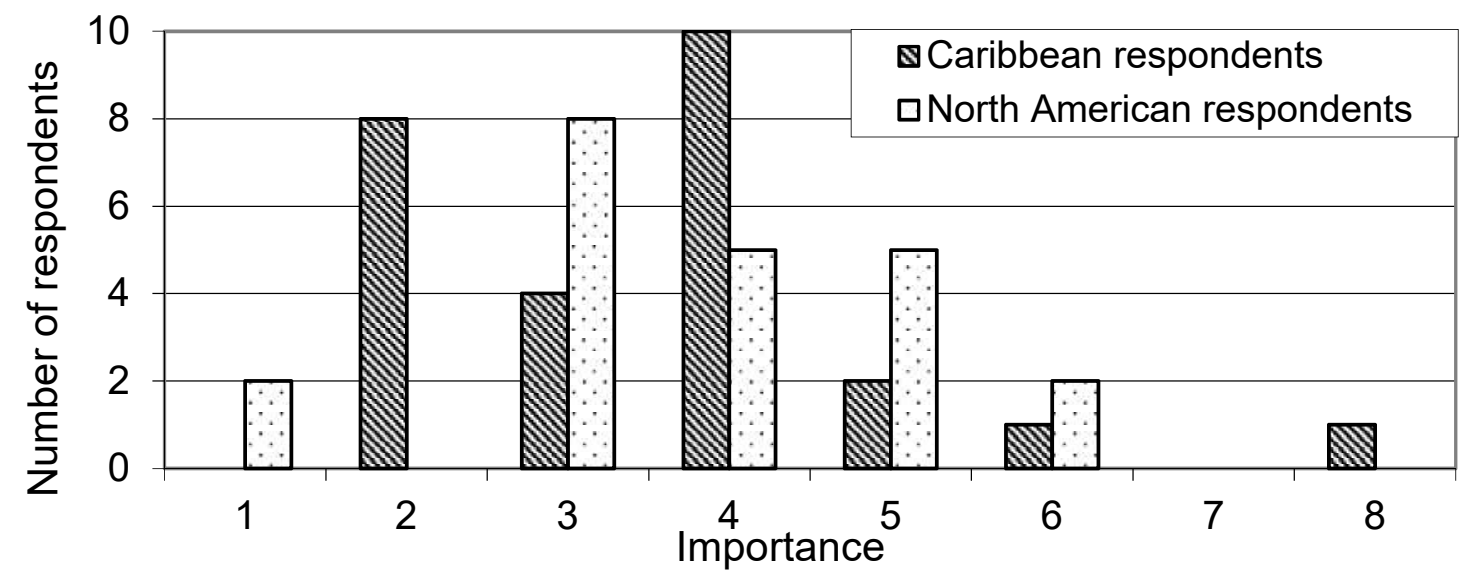

Figure 5: Sharing of risk and/or profits 
Formation of an ICJV is one way in which firms in lesser-developed countries may gain access to technological capabilities. As shown in Figure 6, Access Technology was ranked number 2 by the ESC firms and number 8 by the NA companies. On the other hand, the NA company may be passing this knowledge to a future competitor (CII 1993); however, this was not a great concern of the NA respondents interviewed as only a minimal amount of their total work came from outside North America.

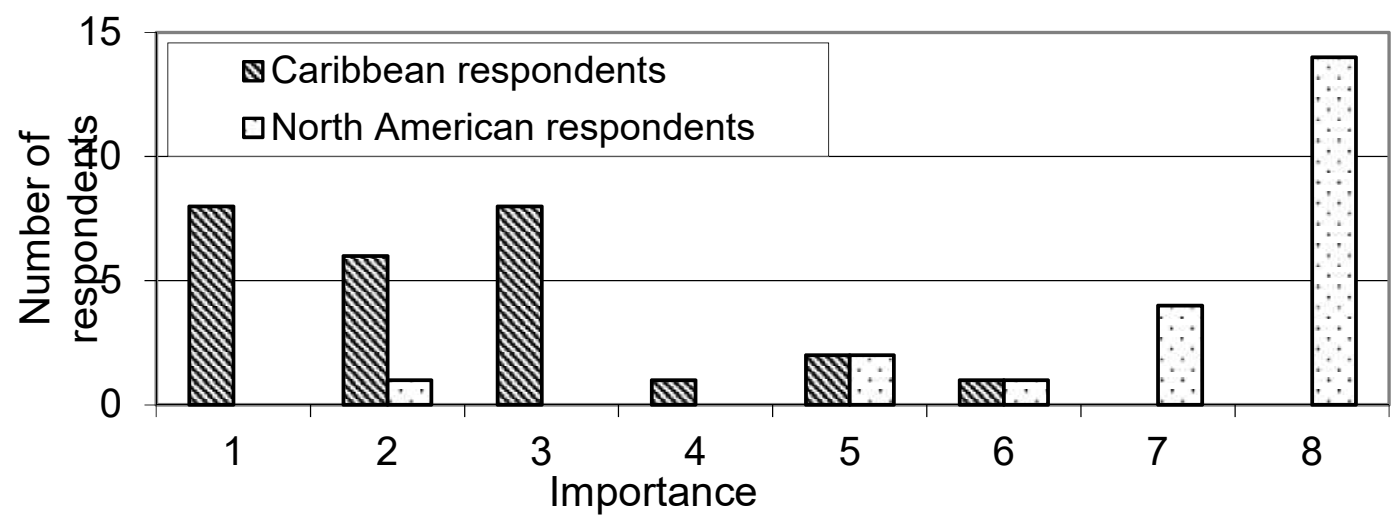

Figure 6: Access Technologies

During an interview of one North American firm, it was indicated that the joint ventures were undertaken because one of their main clients wanted to perform work overseas and requested their service. The aid of a company local to the investment helped achieved the work. This criterion, shown in Figure 7 , was ranked $6^{\text {th }}$ by the North American companies and $4^{\text {th }}$ by the ESC companies; however no company from the Caribbean gave it a value of 1 whereas 3 North American firms noted it as their most important reason.

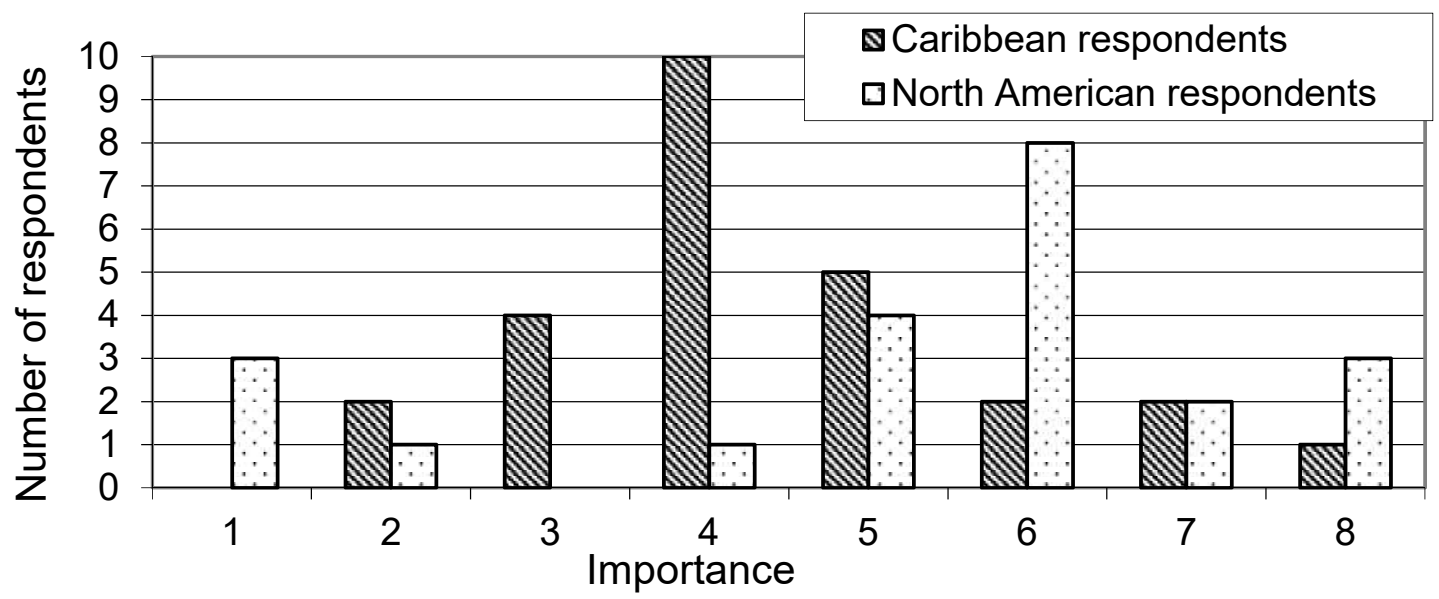

Figure 7: Serve core customers

The formation of an ICJV with a local firm who has been operating in that area for a long time allows the international firm to understand and adapt to the local conditions much faster than if they were working on their own. Learn local market was ranked at number 3 by the North American firms and number 8 by the Caribbean firms. Two of the 22 international firms noted this to be their main reason for entering the international joint venture, as shown in Figure 8. 


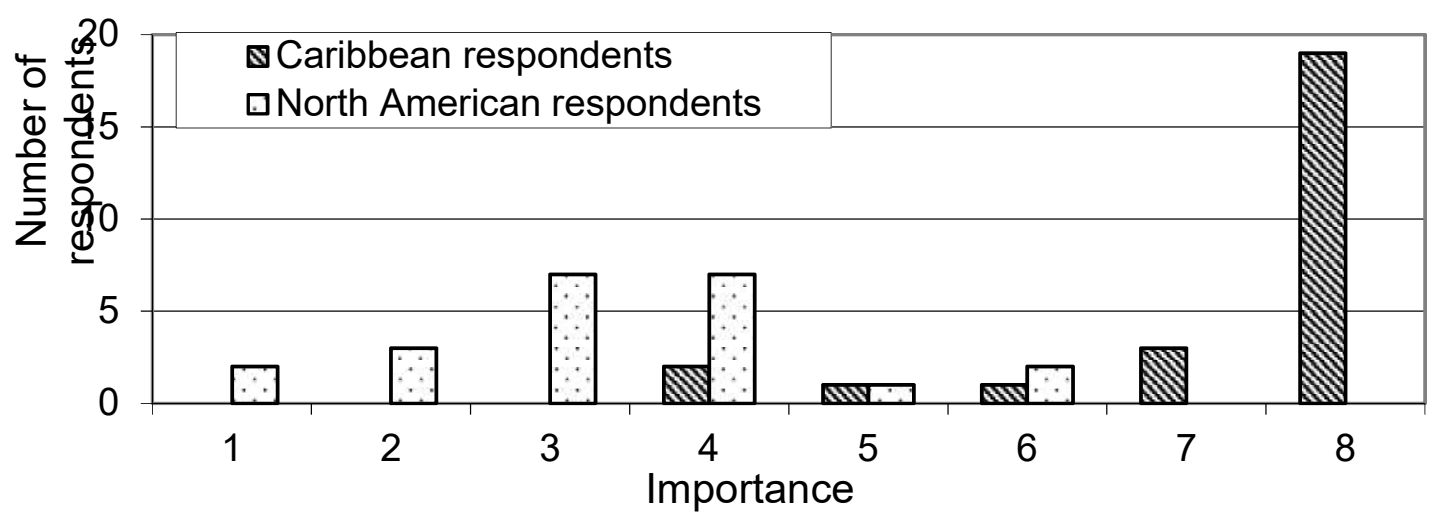

Figure 8: Learn local markets

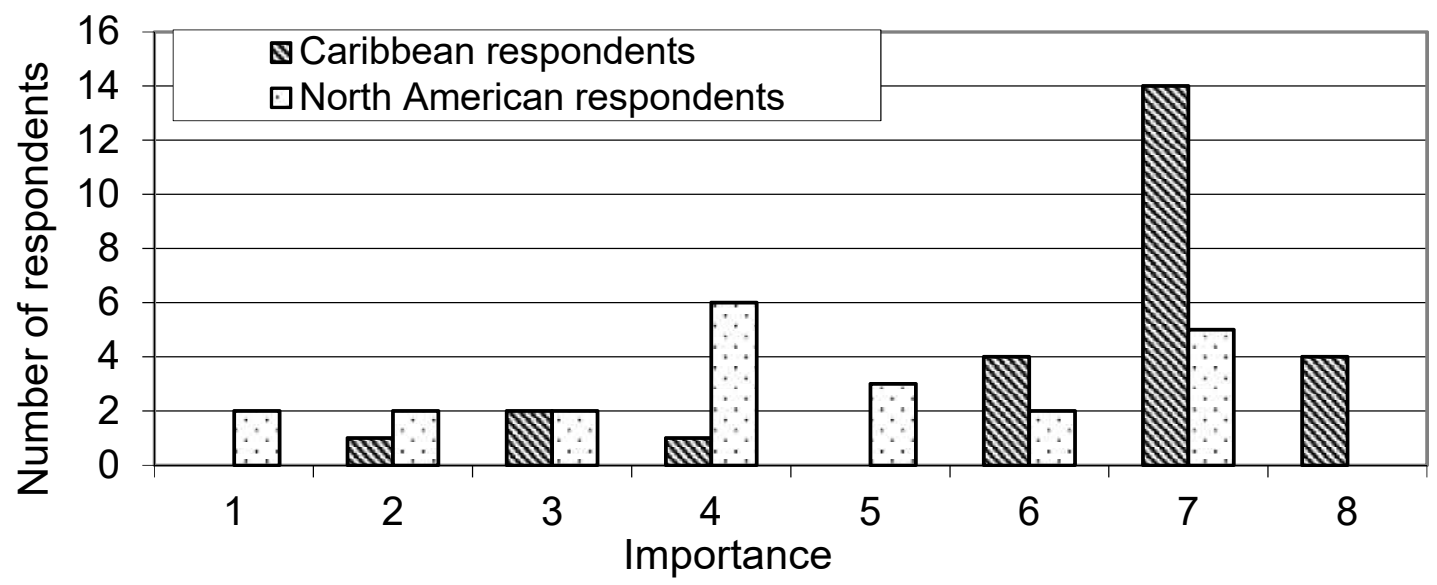

Figure 9: Meet foreign government requirements

Some governments, primarily in the Middle East, Southeast Asia and Australia (CII 1993), insist that a local company be involved for an international firm to be awarded a project to ensure technologies and expertise that are not present in that country to be acquired by the local industry. This criterion was ranked number 5 by the NA firms and number 7 by the ESC firms. This is one of the barriers that have been removed by the international free trade agreements between several countries including most of those in the ESC. Two of the 22 NA firms surveyed gave it a value of 1 , as depicted in Figure 9.

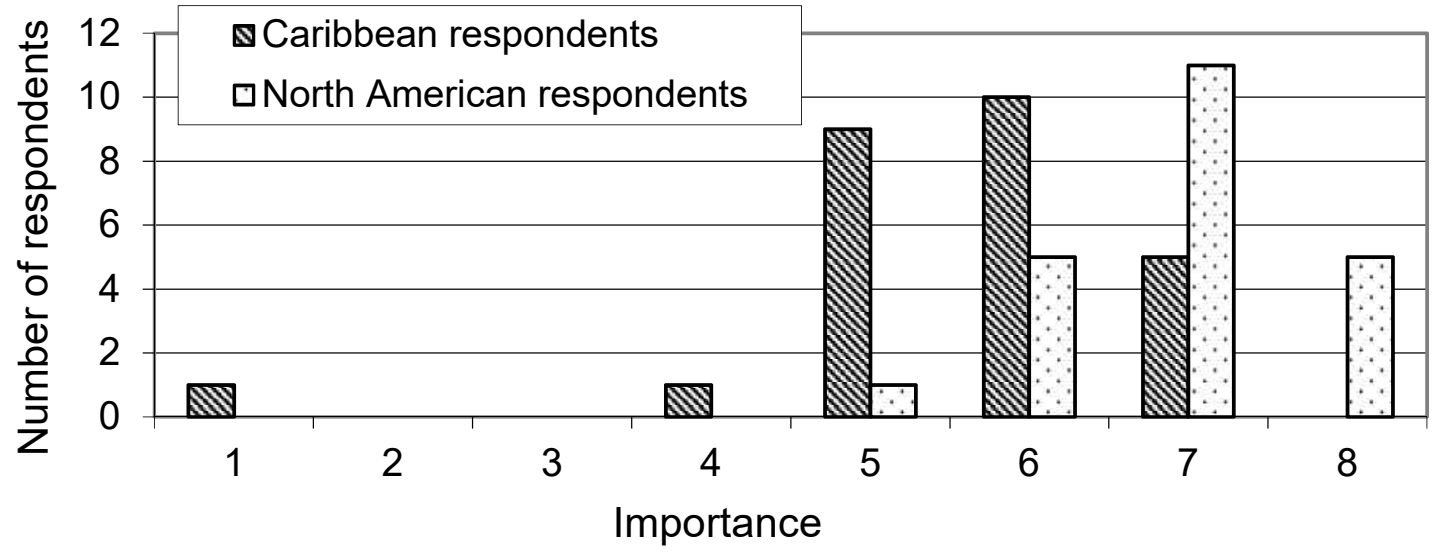

Figure 10: Secure financing 
Joint ventures are seen as a means of increasing bonding capacity, however, this will require all major partners in the joint venture to be accountable for the capital received (CII, 1993a). As shown in Figure 10, only one company ranked Secure Financing higher than fourth.

\section{Benefits of joint ventures}

The method used to obtain and analyze the seven main benefits of forming ICJV (CII 1993) was similar to that used in Section 2. The ranks and mean scores are shown in Table 8. Enhance competitive position was the most important benefit to both groups of companies.

Enhance competitive position was ranked at 1 by both North American and Caribbean companies. As shown in Figure 11, eight NA firms and eleven ESC firms identified it as the main benefit. Obtaining new work was ranked 3rd by the Caribbean companies and ranked 2 nd by the North American firms. Three Caribbean and five North American companies identified it as the main benefit gained, as shown in Figure 12. A firm's market share may be increased by the formation of joint ventures as new projects are obtained, leading to that firm becoming more dominant in that market (CII 1993). Figure 13 shows that four ESC and two NA firms identified it as their main benefit.

Table 8: Benefits gained from forming joint ventures

\begin{tabular}{lcccc}
\hline \multirow{2}{*}{ Factors } & \multicolumn{2}{c}{ Caribbean } & \multicolumn{2}{c}{ North American } \\
& Rank & Mean & Rank & Mean \\
\hline Enhance competitive position & 1 & 1.9 & 1 & 2.5 \\
Obtaining new work & 3 & 3.5 & 2 & 3.2 \\
Increase in market share & 2 & 2.8 & 3 & 3.9 \\
Increase in profits & 4 & 3.7 & 6 & 4.6 \\
Broaden client base & 5 & 4.4 & 4 & 4.2 \\
The sharing of risks & 6 & 4.9 & 5 & 4.6 \\
Learning new cultures & 7 & 6.8 & 7 & 4.8 \\
\hline
\end{tabular}

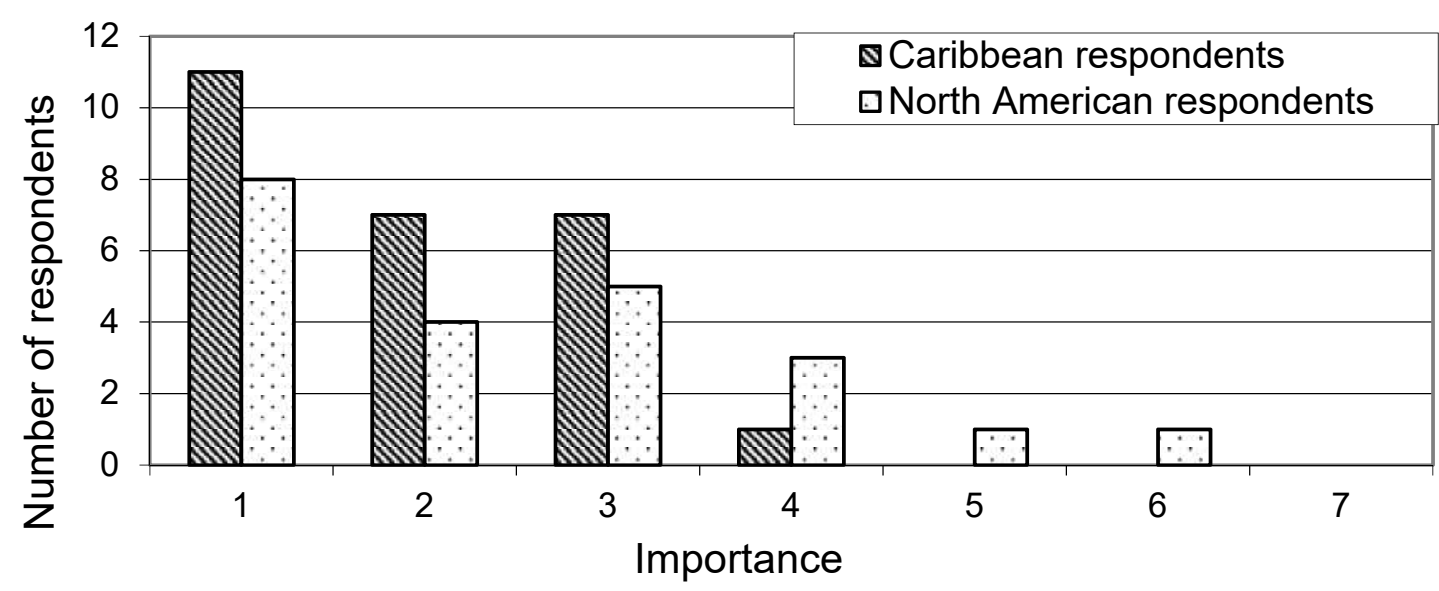

Figure 11: Enhance competitive position 


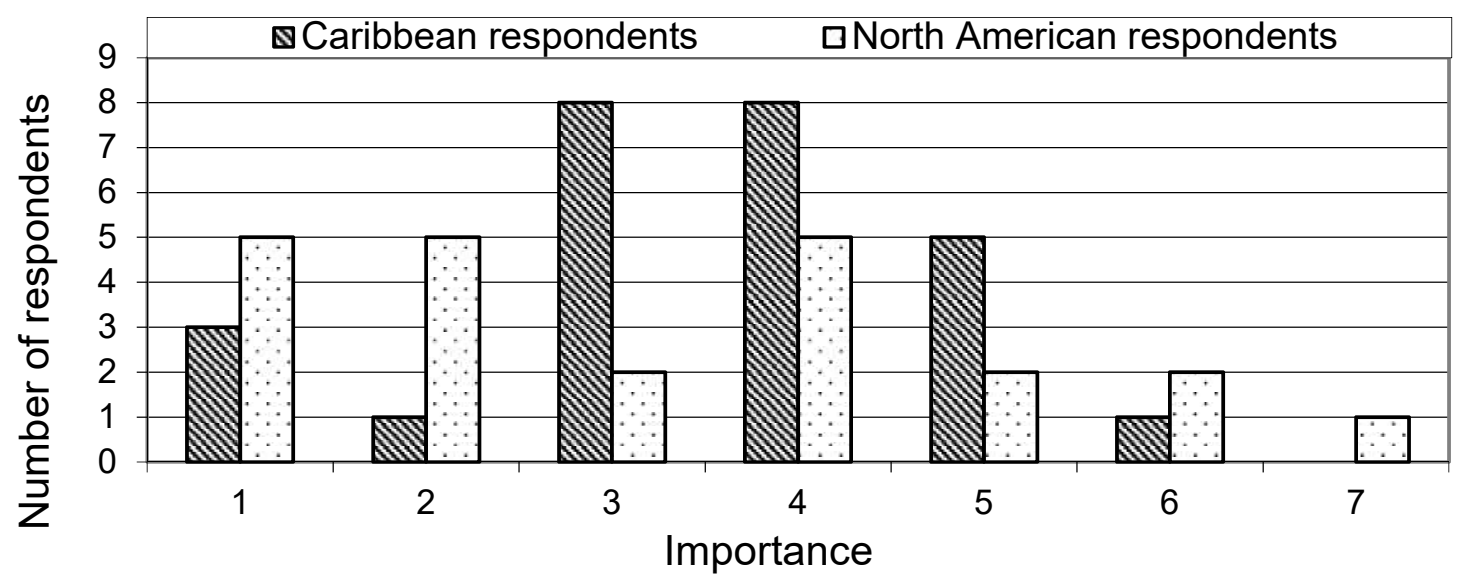

Figure 12: Obtaining new work

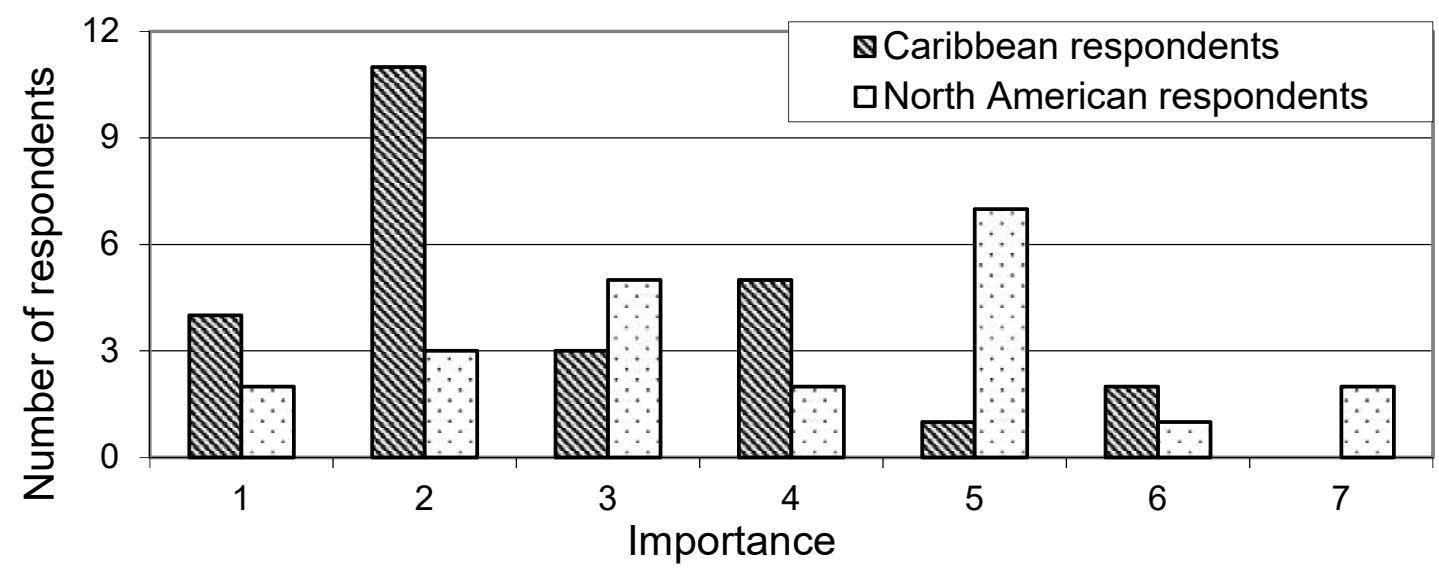

Figure 13: Increase in market share

All businesses aim to make a profit, therefore forming joint ventures must be seen as one way of achieving this goal. This criterion was ranked 6 th by the NA companies and 4 th by the ESC companies, as shown in Figure 14. Interviewees noted that an increase in profit is not always achieved with the first ICJV project undertaken. Several companies noted that ICJVs give them opportunities to reach and provide service to a wider range of clients than they would normally meet before entering into these ventures. With the new relationships established, they are often invited to bid on and at times asked to negotiate for new work with the clients. As shown in Figure 15 , there was no clear consensus on this factor.

As mentioned, conducting work in a new market can be very risky and could eventually be very costly for a firm. This criterion was ranked 5 by the NA firms and 6 by the ESC firms. Three of the 26 ESC respondents and 2 of the 22 NA firms identified it as their main benefit (Figure 16). Joint ventures allow a firm to gain cultural awareness and get insight to the intricacies of the market from their local partner. This benefits the firm if they intend to develop a long term working relationship in that country. Learning of new culture, shown in Figure 17, was ranked $7^{\text {th }}$ by both groups. 


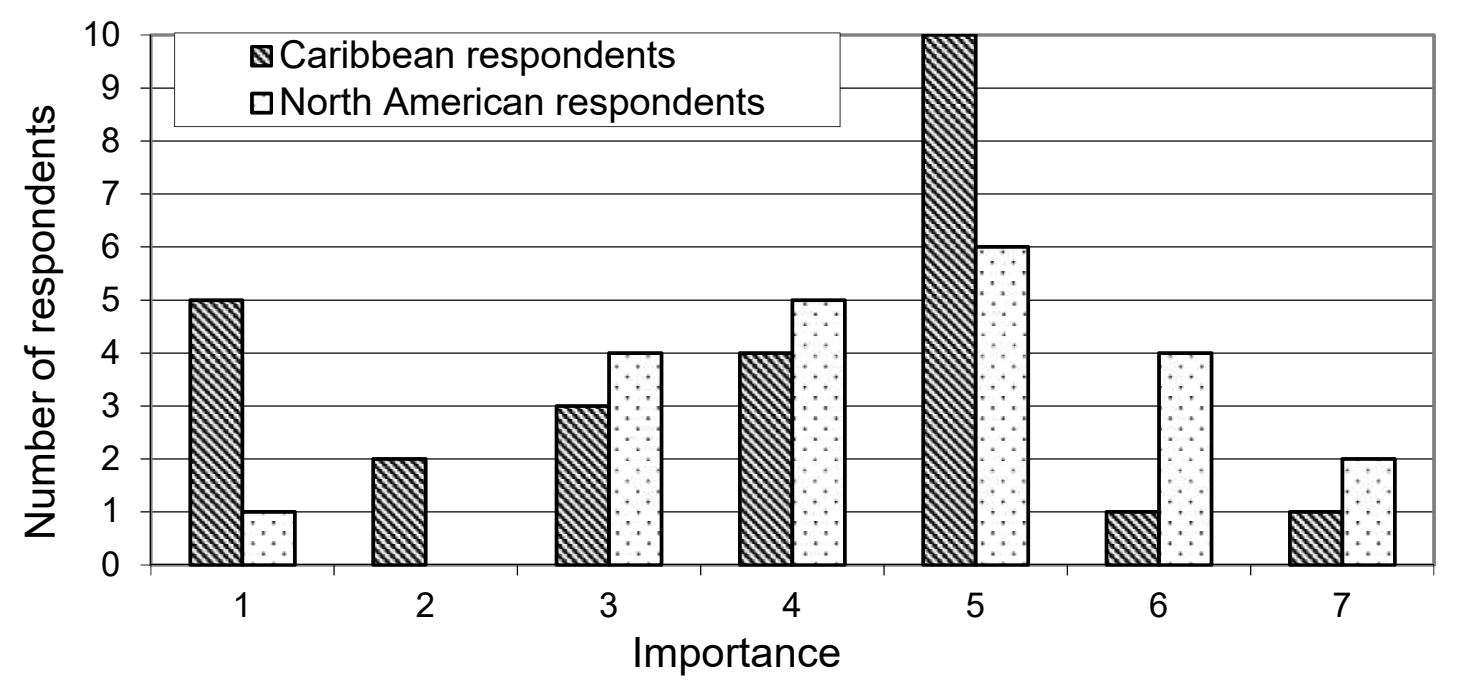

Figure 14: Increase in profits

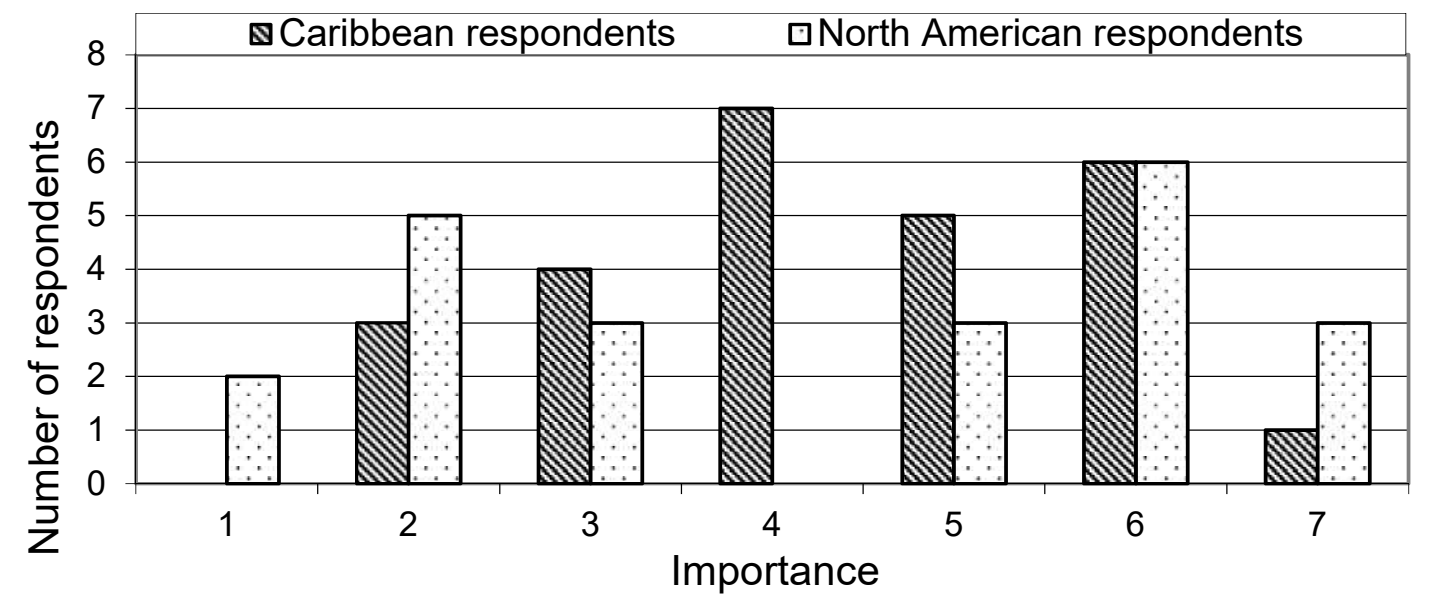

Figure 15: Broaden client base

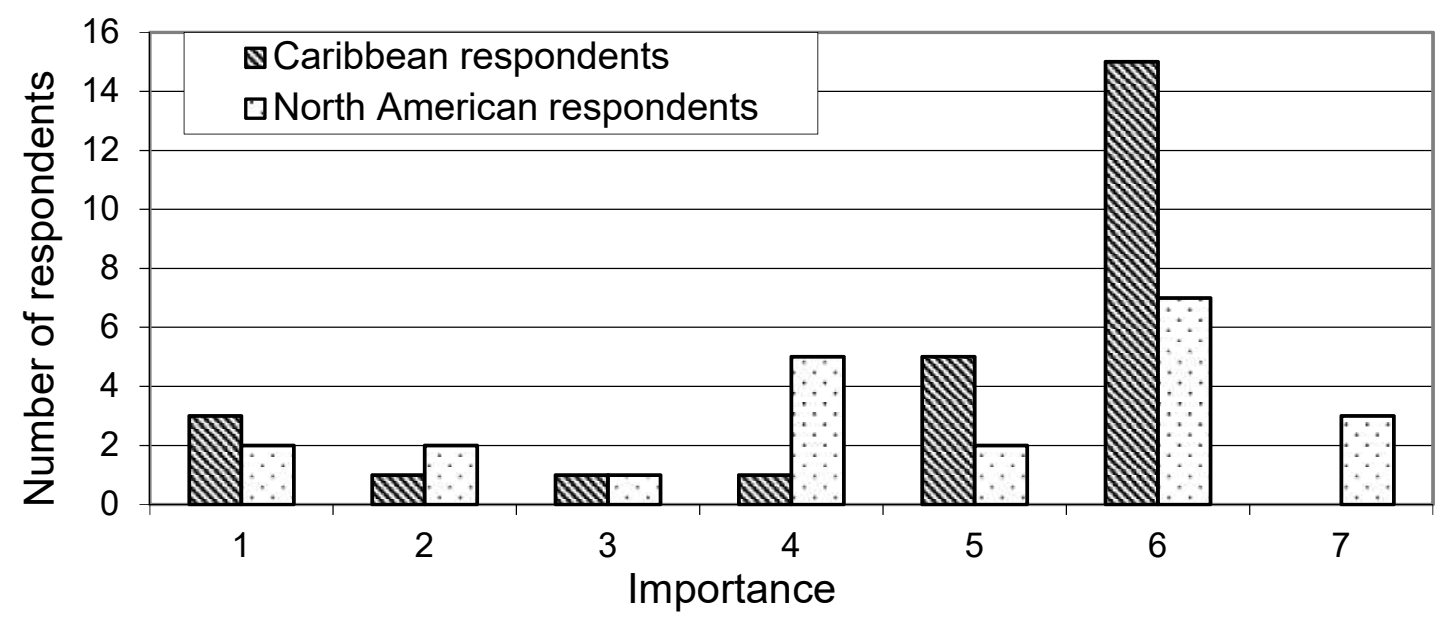

Figure 16: The sharing of risks 


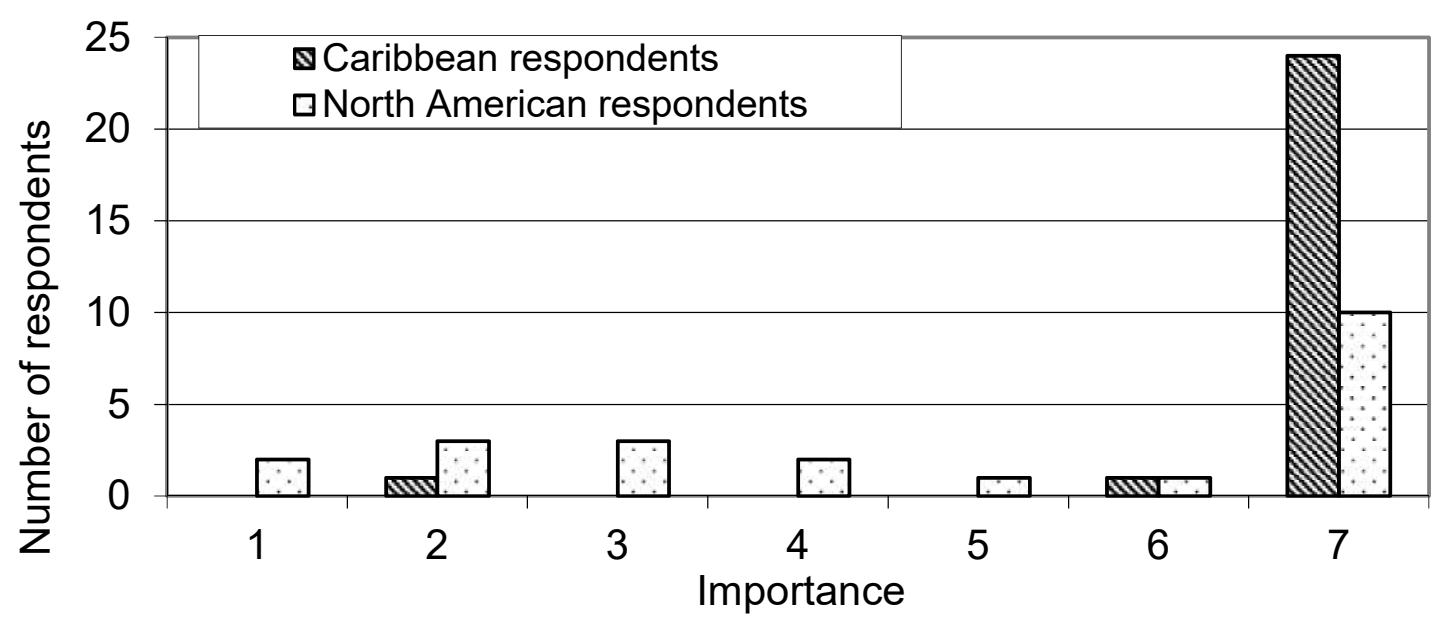

Figure 17: Learning of new culture

\section{Ranking Major Risk Factors and Strategies for Mitigating the Top Ten}

The risk significance index (RSI) developed by Shen et al. (2001) to show the relative significance among the risks associated with ICJV in Chinese construction procurement practices was used in this research. Each respondent was asked to evaluate two characteristics of each risk: a) the likelihood of risk occurrence: $\alpha$, and, b) the degree of impact or the level of loss if the risk occurs: $\beta$. The RSI, shown in Eq. 1 , is calculated by converting the three-point scales for $\alpha$ (lowmoderate-high) and $\beta$ (small-moderate-large) into numerical scales. The scale chosen along with the matrix for the RSI are shown in Table 9.

Table 9: Matrix for the calculation of the RSI

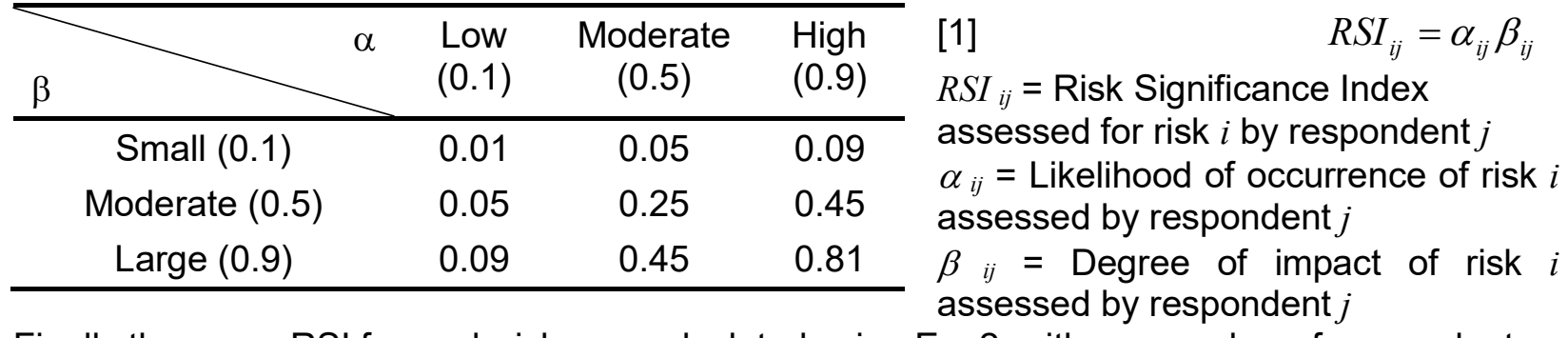

Finally the mean RSI for each risk was calculated using Eq. 2, with $n=$ number of respondents.

$$
M R S_{i}=\frac{\sum_{j=1}^{n} S R I_{i j}}{n}
$$

The risks are shown in Table 10 in three ways. First, the overall rank is determined by calculating the MRS for the overall group. Second, the MRS is calculated using only the North American responses (NA). Finally, the MRS is calculated using only the Caribbean responses (ESC). Where the difference between the NA and ESC means is between 0.05 and 0.09 inclusive, the Overall Rank column is marked with an asterisk; where that difference is 0.10 or greater, it is marked with a double asterisk. The limits for identifying appreciable differences were determined arbitrarily based on the data. 
It is interesting to note that the top ten risks were the same for each group, although the MRS was notably different in three cases and the ranking changed slightly. This implies that there is a reasonably close matching between the two groups of the risk perceptions.

Table 10: Scored risk factors

\begin{tabular}{|c|c|c|c|}
\hline \multirow{2}{*}{$\begin{array}{l}\text { Overall } \\
\text { Rank }\end{array}$} & \multirow[t]{2}{*}{ Risk factors } & \multicolumn{2}{|c|}{$\begin{array}{l}\text { Mean Risk } \\
\text { Significance }\end{array}$} \\
\hline & & NA & ESC \\
\hline $1^{* *}$ & Loss due to bureaucracy for late approvals & 0.42 & 0.57 \\
\hline 2 & Project delay & 0.47 & 0.48 \\
\hline 3 & Client's cash flow problems & 0.40 & 0.42 \\
\hline $4^{*}$ & Industrial disputes & 0.38 & 0.47 \\
\hline $5^{*}$ & Security problems at project site & 0.36 & 0.44 \\
\hline 6 & Loss incurred due to government/political changes & 0.38 & 0.38 \\
\hline 7 & Cost increase due to changes in government policies \& laws & 0.35 & 0.38 \\
\hline 8 & Increase of labour cost & 0.36 & 0.36 \\
\hline $9^{*}$ & Increase materials price & 0.38 & 0.32 \\
\hline 10 & Excessive demand for design changes \& variation from client & 0.33 & 0.32 \\
\hline 11 & Unfairness in tendering & 0.30 & 0.32 \\
\hline 12 & Poor relations with government departments & 0.29 & 0.32 \\
\hline $13^{*}$ & Increase in project management overheads & 0.32 & 0.25 \\
\hline 14 & Increase in site overheads & 0.27 & 0.28 \\
\hline 15 & Poor relation and disputes with partners & 0.27 & 0.25 \\
\hline 16 & Improper project planning and budgeting & 0.25 & 0.24 \\
\hline $17^{*}$ & Low credibility of shareholders and lenders & 0.28 & 0.23 \\
\hline 18 & Improper project feasibility study & 0.20 & 0.23 \\
\hline 19 & Incompetence of project management team & 0.20 & 0.21 \\
\hline 20 & Errors in design drawings & 0.21 & 0.23 \\
\hline $21^{*}$ & Materials shortage & 0.25 & 0.20 \\
\hline 22 & Loss incurred due to corruption and bribery & 0.23 & 0.20 \\
\hline 23 & Inadequate project organization structure & 0.22 & 0.19 \\
\hline 24 & Unusual weather and force majeure & 0.20 & 0.20 \\
\hline $25^{\star *}$ & Increase of accessory facilities price & 0.14 & 0.25 \\
\hline $26^{\star *}$ & Shortage of skilled workers & 0.27 & 0.12 \\
\hline $27^{* *}$ & Loss due to fluctuation of inflation rate & 0.13 & 0.24 \\
\hline $28^{*}$ & Problems due to partners' different practices & 0.21 & 0.16 \\
\hline $29^{*}$ & Inadequate forecast about market demand & 0.22 & 0.16 \\
\hline 30 & Unknown site physical conditions & 0.20 & 0.17 \\
\hline 31 & Equipment failure & 0.17 & 0.19 \\
\hline 32 & Increase of resettlement costs & 0.19 & 0.16 \\
\hline 33 & Subcontractor's low credibility \& incompetence & 0.19 & 0.17 \\
\hline 34 & Incomplete contract terms with partners & 0.15 & 0.16 \\
\hline $35^{*}$ & Loss due to fluctuation of local currency's exchange rate & 0.12 & 0.20 \\
\hline 36 & Local protectionism & 0.14 & 0.18 \\
\hline 37 & Inadequate choice of project partner & 0.16 & 0.17 \\
\hline $38^{*}$ & Labour, materials \& equipment import restriction & 0.19 & 0.14 \\
\hline 39 & Fall short of expected income from project use & 0.14 & 0.13 \\
\hline $40^{*}$ & Loss due to fluctuation of interest rate & 0.10 & 0.18 \\
\hline
\end{tabular}




\begin{tabular}{llcc}
\hline & & \multicolumn{2}{c}{ Mean Risk } \\
Overall & Risk factors & \multicolumn{2}{c}{ Significance } \\
Rank & & NA & ESC \\
\hline $41^{* *}$ & Restrictions on funds repatriation & 0.09 & 0.20 \\
42 & Breach of contracts by other participants & 0.17 & 0.13 \\
$43^{*}$ & Breach of contract by project partner & 0.18 & 0.11 \\
44 & Uncertainty and unfairness of court justice & 0.13 & 0.14 \\
45 & Change of organization within local partner & 0.13 & 0.12 \\
46 & Shortage in supply of water, gas, and electricity & 0.11 & 0.15 \\
47 & Lack of enforcement of legal judgement & 0.12 & 0.14 \\
48 & Hazards of environmental regulations & 0.15 & 0.11 \\
49 & Difficult convertibility of local currency & 0.11 & 0.11 \\
50 & Poor quality of procured materials & 0.11 & 0.12 \\
51 & Competition with other similar projects & 0.13 & 0.11 \\
$52^{*}$ & Local firm's incompetence and low credibility & 0.16 & 0.08 \\
53 & Accidents on site & 0.10 & 0.13 \\
54 & Loss due to insufficient law for joint ventures & 0.10 & 0.11 \\
55 & Poor quality of procured accessory facilities & 0.12 & 0.10 \\
56 & Improper selection of project location & 0.12 & 0.10 \\
57 & Obsoleteness of building equipment & 0.11 & 0.09 \\
$58^{*}$ & Shortage in accessory facilities & 0.12 & 0.07 \\
$59^{*}$ & Incompetence of transportation facilities & 0.12 & 0.07 \\
60 & Improper selection of project type & 0.10 & 0.08 \\
61 & Bankruptcy of project partner & 0.07 & 0.10 \\
62 & Disagreement on accounting of profits and loss & 0.09 & 0.08 \\
63 & Technology transfer dispute & 0.06 & 0.07 \\
64 & Problems associated with culture \& religion difference & 0.06 & 0.05 \\
\hline & & &
\end{tabular}

\section{Management risks}

Project delay was ranked second by ESC companies, first by the NA group, and second overall. The project's completion may be delayed due to various reasons, only some of which are controllable by the joint venture. Proactive project management is generally more effective than reactive systems and this can only be achieved if the personnel in charge of the project are experienced and insightful to anticipate problems and implement a strategy to deal with them. Therefore, efforts should be taken to ensure the project is staffed with competent personnel. Assigning junior staff to the project to give them international experience was noted as a major cause for concern; this normally leaves the local partner stuck with the consequences. The nature of the team, such as incompatibility of core cultures in which the NA team members are not accustomed to the local culture and traditions is a major concern. Problems may occur if one partner is unable to honour their side of the agreement or if there are unrealistic time lines.

\section{Policy and political risks}

In the top ten, there are three policy and political risks: loss due to bureaucracy for late approvals, loss incurred due to government / political changes, and, cost increase due to changes in government policies laws and regulations, ranked 1, 6 and 7 overall. The ESC firms were significantly more concerned about late approvals for permits. For this reason, international firms entering the ESC market, especially for the first time, should seek out local partners who have a good relationship with the government agencies responsible for granting licenses and permits. 
Interviewees recommended that NA firms planning to enter a joint venture in this region be aware of the stability of the ruling government. They should investigate if the project is being done for political gain and if the opposition, who may form the government during the life of the project, supports it. Contract clauses may not be adequate protection and it is therefore recommended that the firm forego projects where cancellation of the project is a real possibility.

\section{Financial risks}

The third most critical risk factor is a financial one: client's cash flow problems. This often involves the client's ability to fund the project through to completion or to make timely payment upon submission of invoices. International firms operating in developing countries claim that one of the most critical risks they face is delayed or non-payment (Rashid 1991), an issue that has been confirmed in this research. This problem also exists if the government is the client and tends to worsen if the stability of that government is at risk. With this in mind, the joint venture should be selective with which clients they seek to conduct business, and because contract clauses may not be sufficient protection; foregoing the project may be the best option.

\section{Market risks}

Increase in labour cost and increase in materials price are market risk factors and were ranked at 8 and 9 respectively. These risks could have a great effect on the profitability of the joint venture. It was noted by the interviewees that the type of contract is of great importance and that fixed price contacts in the ESC should be avoided.

\section{Site risks}

Industrial disputes and security problems at project site rank $4^{\text {th }}$ and $5^{\text {th }}$ overall respectively whereas excessive demand for design changes \& variation from client ranked 10 . It is important to note that the ESC partners were much more concerned about this than the NA group, perhaps because the ESC partner has to deal with these issues on a daily basis and have a greater understanding of its likelihood of occurrence and impact on a project; several projects in the ESC have been affected by industrial disputes resulting in workers taking strike action. It is recommended that communication with the workers' union be carefully maintained to reduce this risk. The problem of site security is at times complex and therefore it is advised that the existing security environment be identified prior to submitting the bid so that the cost of additional security can be included. The effects of client-driven changes are the disruption of work, changes in work allocation among the partners, and increased claims (Bing et al. 1999). Ensuring that the appropriate clauses are included in the contract with the client may be the best protection.

\section{Differences in Risk Perception}

The issue of differences in MRS is important because it implies differences in perceptions of risk. These can become a source of conflict, and it may be worthwhile addressing these risks early in the ICJV. Twenty, or almost $1 / 3$ of the risk factors had a MRS difference between the two groups of 0.05 or greater.

The greatest discrepancies were \#1: loss due to bureaucracy for late approvals where the ESC group considered this to be a much greater risk, perhaps because of familiarity with local conditions, and risk \#26: shortage of skilled workers, where the NA group considered this factor a greater risk than the ESC group. Interviewees noted that NA firms should be aware of the ESC firm's ability to obtain a qualified work force to carry out the required tasks.

Three factors have a difference in risk index score of 0.11: \#25 increase of accessory facilities price, \#27 loss due to fluctuation of inflation rate, and \#41 restrictions on funds repatriation. In all 
three cases, the ESC group considered these to be a greater risk than the NA group, but also in all three cases, these factors are out of their control.

In the top ten, three factors have a difference of MRS between 0.05 and 0.09 , namely, industrial disputes, security problems at project site, and, increase materials price. The ESC firms found the first two to be of greater concern whereas the NA firms were more concerned about stability of the price of materials. This may be related to the stable labour market generally experienced by NA firms and their expectation that it would be reasonably similar in the ESC.

\section{Success Factors}

The following factors were identified during interviews as important success factors.

All of the interviewees noted that the main ingredients for a successful international joint venture are ensuring that high levels of trust and cooperation are involved. Trust, once breached, cannot be regained. It is therefore vital that each partner be straightforward in any business involving the venture. Several companies consider equity between the partners to be very important, i.e. the sharing of responsibilities and risks and mutual respect. Joint ventures where one partner is dominant have been shown to have a much better success rate than shared management ventures (Bing et al. 1999), however, this concept was not supported by the ESC companies who strongly oppose a master/servant relationship with foreign partners. One respondent from the Caribbean noted that if the local partner is not assigned a substantial part of the work, it might lead to a breakdown in the joint venture relationship. Note that one of the main incentives of the ESC firms was to access technology; this is not being achieved if the NA company handles the major portion of the design work. In these cases, they are only allowed to view the finished product instead of having a hand in and learning how to undertake such designs. A joint venture partner that is suitable for one project may not be the most suitable for another project. Firms should seek partners that specialize in areas of expertise that are complementary or compatible for the specific project.

For firms entering an ICJV with a partner for the first time should ensure that they develop a well thought out agreement, with focus on risks, liabilities and profits prior to commencement of work. This document should be clear with an undeniable understanding of the core project requirements, as mutually agreed beforehand. One interviewee from the Caribbean noted that noncompliance with the contract terms tends to occur when terms in the written agreement are different from those discussed and agreed upon verbally. These issues are best dealt with amicable and are normally settled by negotiation.

\section{CONCLUSIONS}

This research identified the major criteria for, benefits of, and risk factors associated with forming international joint ventures in the English-speaking Caribbean. The risk significance index enabled the most critical risks to be scored and ranked. Interviews provided suggestions for mitigating the top ten risks.

The top three drivers for forming ICJV are to improve competitive positions, enter new markets, and share risks and/or profits. The top three benefits of the ICJV are enhancement of competitive position, obtain new work, and to increase market share. There was some correlation between drivers and benefits. For example, the prime driving force was also believed to be the most important benefit. 
The top three risks were loss due to bureaucracy for late approvals, project delay, and client's cash flow problems. The top ten risks for the two groups were identical although the mean risk significance indexes (MRS) were appreciably different in a few cases, and ranks changed slightly.

The risk factors that received a MRS difference of 0.1 or greater are of specific concern because they depict a difference in perception and may become a source of friction between the partners. Five of these factors were identified, namely, \#1: loss due to bureaucracy for late approvals, \#25 increase of accessory facilities price, \#26: shortage of skilled workers, \#27 loss due to fluctuation of inflation rate, and \#41 restrictions on funds repatriation.

\section{ACKNOWLEDGEMENTS}

The authors respectfully acknowledge the financial support of the Greater Toronto Airports Authority in conjunction with NSERC Industrial Oriented Research Grant \# 216754-98 in this research. The authors also sincerely thank the participants of the survey.

\section{REFERENCES}

Bing, L., Tiong, R.L., Fan, W.W. and Chew, D.A., 1999. Risk management in international construction joint ventures. Journal of Construction Engineering and Management, 125(4):277284

ClI, 1993. Alliances in International Construction. The International Construction Task Force, Construction Industry Institute, Arizona State University, Temple, Arizona

Rashid, A.A.A., 1991. Global strategies of construction firms. PhD thesis. Dept. of Construction Management \& Engineering. University of Reading, UK.

Shen, L.Y., Wu, G.W.C. and Ng, C.S.K., 2001. Risk assessment for construction joint ventures in China. Journal of Construction Engineering and Management, 127(1):76-81

Tulacz, G.J., 2000a. The problems of working abroad make contractors more selective. ENR May 22, 2000, 135-138.

Tulacz, G.J., 2000b. \$3.4 Trillion: US Constructions boom leads the way in expansion of global spending. ENR December 4, 2000, 30-5 